\title{
Preparation and Electrical Properties of CB/PVC/EPDM Conductive Foam Composite
}

\author{
Xiuqi Liü ${ }^{1,}$, Heqin Xing ${ }^{2, b}$, Lili Zhao ${ }^{1, a}$, Xishuang Chen $^{1, \text { a }}$ \\ ${ }^{1}$ College of Food Science and Engineering, Jilin Agricultural University, Changchun, Jilin, 130118, \\ China \\ ${ }^{2}$ College of Quartermaster Technology, Jilin University, Changchun, Jilin, 130062, China \\ aliuxiuqi2004@yahoo.com.cn, ${ }^{b}$ xinghq@jlu.edu.cn
}

Keywords: Electrical property, CB, PVC, EPDM, Foam composite.

\begin{abstract}
In our study, the electrical conductivity of CB / PVC / EPDM foam composite was made with carbon black, PVC and EPDM by melt blending and molded foam. The bubble structure and resistivity-temperature characteristic were observed. Influences of carbon black content, crosslinker of composite were investigated. When the $\mathrm{CB}$ content was $10 \% \mathrm{wt}$, the obtained foam had good bubble structure and mainly performs NTC effect during heating process. The composite have not only good foam performance but also NTC characteristic.
\end{abstract}

\section{Introduction}

The foam plastic has many valuable properties; it has been widely used in industry, agriculture, transportation, military, industrial, aerospace industry and so on [1-3]. In developed countries, the development of foam plastic production industry was faster, specifically in the United States, Europe, Japan and other countries, yield and variety are increasing rapidly [4]. In China, the plastics industry started relatively late, the foam plastic industry started later, therefore, we need to learn a foreign research achievements, and adapt to the social bubble growing demand.

In recent years, the users and manufacturers of communications equipment, photographic processing equipment, electronic devices have already recognized the need to protect their equipment and devices, and against electrostatic particularly the adverse effects of electrostatic discharge [5]. In order to meet this requirement, a new industrial appeared, called static control industry, the conductive foam (e.g., polyethylene) can be used to provide physical protection for electronic components and the electrostatic protection.

The foaming conductive polymer primarily used its physical properties, high thermal expansion, and a buffering ability and conductivity. It was widely used in the detection of static electricity and the elimination of the electrostatic field, some products and devices have been patented. The foaming conductive polymer was using resistance temperature characteristic and switching characteristics, mainly as PTC, NTC effect. Currently, the resistance temperature characteristic and its principle of the foam conductive composite were reported few. In this study, the resistance-temperature characteristics and influencing factors of the conductive PVC foam were discussed.

\section{Experimental}

Materials. PVC: S-III, Daqing Petrochemical Plastic Factory, China; EPDM: 8600, Exxon Mobil; Conductive carbon black: HG-1P, Huaguang Chemical Factory, China; Azodicarbonamide (AC): Shanghai chemical reagent procurement and supply stations, China; Dicumyl peroxide (DCP), Dioctyl phthalate (DOP), Dibutyl phthalate (DBP), Stearic acid (St) and Zinc stearate (Zn-St): Shanghai Chemical Co., China; Liquid olefin: Zhenhai Institute of Applied Chemistry, China.

Preparation of CB / PVC / EPDM Foam Composite. Carbon black, PVC, EPDM, DOP and other additives were mixed uniform, placed the blend in a vacuum oven for 1 hour at $80^{\circ} \mathrm{C}$. And then the blend was melting blended on a closed mill for $20 \mathrm{~min}$ at $125^{\circ} \mathrm{C}$, after that the composite was 
taken out and masticated on an open mill for $5 \mathrm{~min}$ and stabilized to remove the strain overnight (24h if possible) before being vulcanization. After 24 hours at room temperature, the samples were crushed to pieces 12 minutes at $10 \mathrm{MPa}$; the temperature was $160{ }^{\circ} \mathrm{C}$. Finally, the CB / PVC / EPDM foam composite were prepared.

Measurement of Volume Resistivity ( $(\mathbf{)})$. Volume resistance R of the direction of the specimen thickness was tested with a second electrode. The both ends of sample were coated with conductive silver glue to ensure good contact of the sample with copper electrodes. VC-9808 digital multimeter was used for measure resistance, volume resistivity was converted using the following expression:

$$
\mathrm{P}=\mathrm{R} \times \mathrm{S} / \mathrm{L}(\Omega \cdot \mathrm{cm})
$$

R: volume resistivity $(\Omega)$; S: surface area of specimen $\left(\mathrm{cm}^{2}\right)$; L: sample thickness $(\mathrm{cm})$

Measurement of Volume Resistivity - Temperature (p-t). The sample was placed in a thermostatic oven, the heating and cooling rate was $2{ }^{\circ} \mathrm{C} / \mathrm{min}$, every $5 \mathrm{~min}$, resistance - temperature changes was record, make the volume resistivity - temperature $(\rho-\mathrm{T})$ curve.

\section{Results and Discussion}

Microstructure of CB / PVC / EPDM Foam Composite. As can be seen by Fig. 1 (a), the apparent morphology and mechanical properties of the foam composite was better, after testing, the foam composite density was approximately $0.267 \mathrm{~g} / \mathrm{cm}^{3}$, so that the composite was a high foaming material.

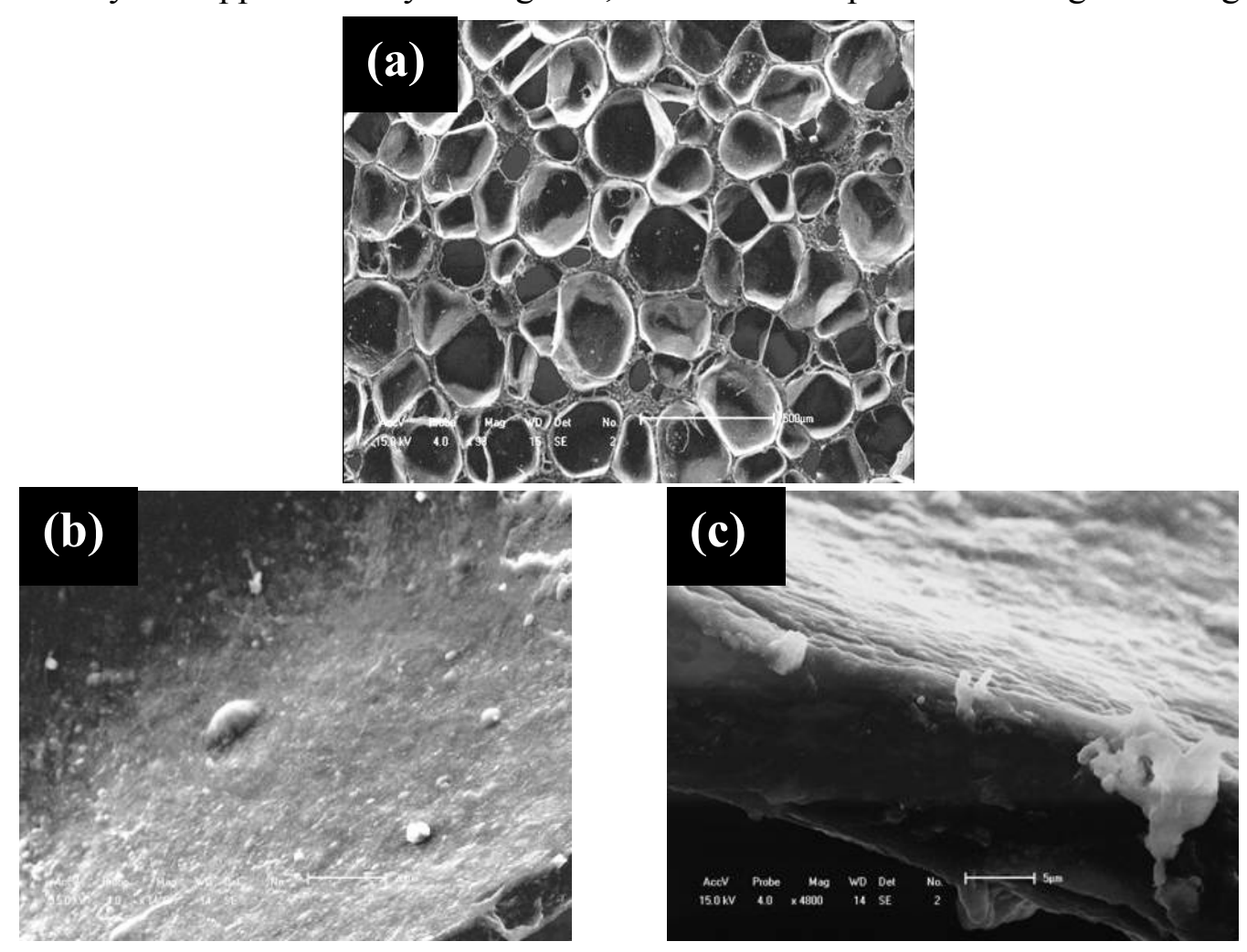

Fig. 1 SEM of CB / PVC / EPDM foam composite (a), cell wall (b) and cell wall thickness (c)

The hole cross-section of the foam was 5 or 6 sided polygon, the cell space was irregular polyhedron, most of the foam structure was closed-cell structure. Bubble average pore diameter was around $250 \mu \mathrm{m}$, the cell was small, uniform, and dense; bubble wall well intertwined to form a honeycomb-like structure. The enlarged SEM pictures of the cell wall were shown in Fig.1 (b) and Fig. 1(c).

Percolation Behavior of CB / PVC / EPDM Foam Composite. For the foam material, the percolation behavior was less obvious. Respect to CB / PVC / EPDM system, when the filling amount was $10 \%-13 \%$, the resistivity of the system was about $10^{6} \Omega$; the filling rate continued to increase, the resistance became lower, reaching $10^{4} \Omega$, corresponding to the resistance-temperature curve was shown in Fig. 2. 


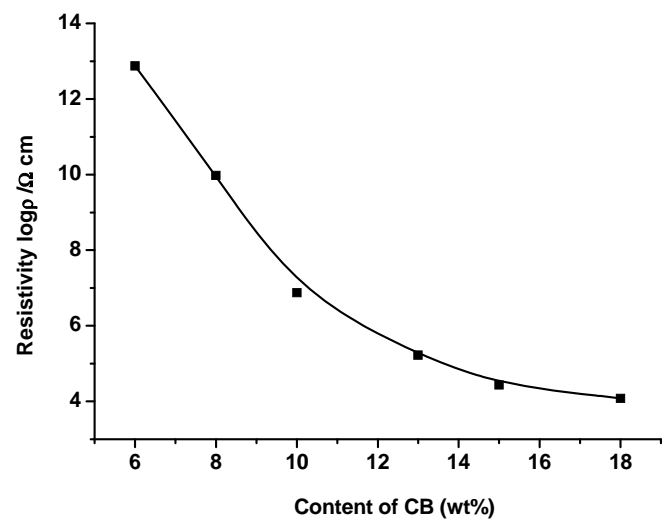

Fig.2 Percolation curve of CB / PVC / EPDM foam composite

Resistance Temperature Characteristic of CB / PVC / EPDM Foam Composite. As shown in Fig. 3, CB / PVC / EPDM foam composite were added 8\%, 10\%, 13\%, 15\%, 18\% super conductive carbon black to test the resistance temperature characteristic. The conductive foam composite showed the NTC effect in the heating process, with the gradual increase in the carbon black content, the room temperature resistivity was reduced accordingly, NTC intensity corresponding was smaller. As for the samples with $13 \%, 15 \%$ and $18 \%$ carbon black content, in the latter half of heating, the samples appeared PTC phenomenon.

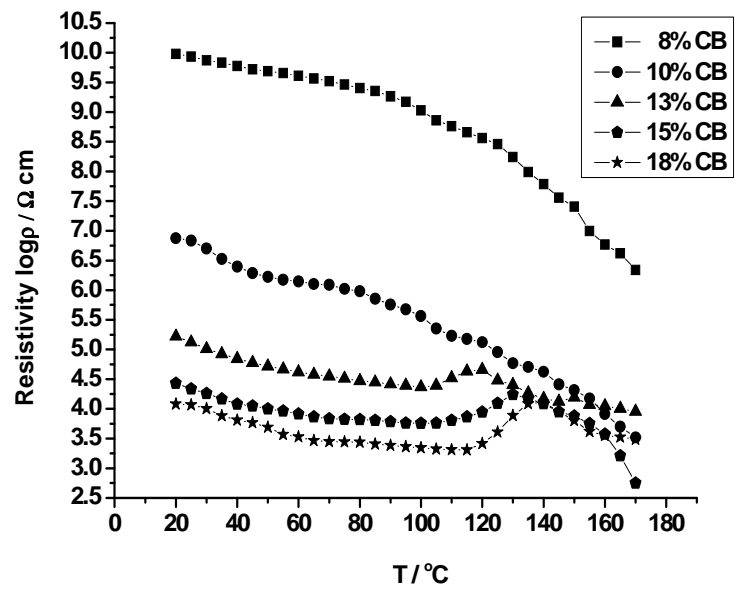

Fig. 3 Resistance-temperature curve of CB / PVC / EPDM foam composite

Effect of DCP Content on Resistance Temperature Characteristic. The cross-linking process was polymer by linear transformed into body the process of the network. The effect of DCP content on resistance temperature characteristic was studied, as shown in Fig. 4 . When the content was 0.25 parts of a crosslinking agent, the content of the crosslinking agent was small, the degree of crosslinking was not enough, the viscoelasticity was small, the gas can not keep, the composite did not form a foamed system. When the crosslinking agent was 0.5 parts, viscoelasticity of the system was poor, Gas bubbles keep weak, likely to cause rupture of the cell wall, the resistance value was high. When the crosslinking agent was 1.25 parts, the system was too large viscoelastic, crosslinked network formed earlier, the distribution of carbon black in the cell wall was relatively dispersed and uniform, resistance value was high, too. When the crosslinking agent content was 0.75 parts and parts, The carbon black was enriched within the cell wall, and more likely to form a continuous conductive path, thereby exhibiting a lower resistance value. 


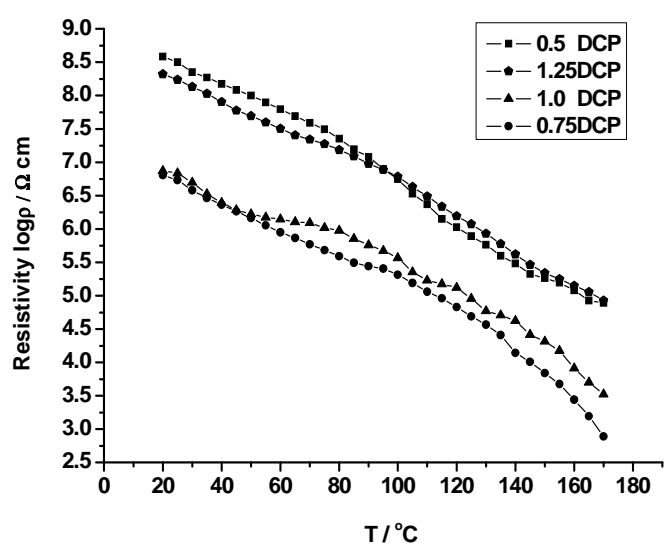

Fig. 3 Effect of DCP content on resistance temperature characteristic

\section{Conclusions}

The apparent morphology and mechanical properties of the foam composite was good, after testing, the composite was a high foaming material. Bubble average pore diameter was around $250 \mu \mathrm{m}$ and a honeycomb-like structure. When the CB filling amount was $10 \%-13 \%$, the resistivity was $106 \Omega$; the $\mathrm{CB}$ content continued to increase, the resistance reached $104 \Omega$. The foam composite showed the NTC effect in the heating process, in the latter half of heating, the samples appeared PTC phenomenon. DCP content has a great impact in the resistance value and the composite cell formation.

\section{Acknowledgements}

This work was financially supported by the Jilin Agricultural University Scientific Research Foundation.

\section{References}

[1] S. Miyauchi, E. Togashi, J. Appl. Polym. Sci. Vol. 30 (1985), p. 2743.

[2] A. Voet, Rubber Chem. Technol. Vol. 54 (1981), p.42.

[3] W. F. Verhelst, K. G. Wolthuis, A. Voet, et al. Rubber Chem. Technol. Vol. 59 (1977), p. 735.

[4] F. Lux, J. Mater. Sci. Vol. 28 (1993), p. 285.

[5] X. P. Bi, Q. C. Ying, R. Y. Qian, Macromol. Chem. Vol. 193 (1992), p. 2905. 